\title{
Molecular evaluation of salt tolerance induced by sodium azide in immature embryos of two wheat cultivars
}

\author{
Mohammed A. Mohammed Ayoob O. Alfalahi* Majed S. Hamedullah** Zahra N. Al Hattab**
}

\author{
Horticulture Department / College of Agriculture / University Of Anbar \\ * Field Crops Department / College of Agriculture / University Of Anbar \\ ** Field Crops Department / College of Agriculture / University Of Baghdad \\ E-mail: mohamadabd378@yahoo.com
}

\begin{abstract}
Background: The artificial induction of mutations represents an efficient tool in creating genetic variations. For this reason, the current study was carried out in the Plant Tissue Culture Laboratory/Genetic Engineering Institute to induce genetic diversity for salt tolerance in two local cultivars of bread wheat (AlIraq and Tamooz 2) using in vitro application of sodium azide (SA).

Objective: Immature seeds from both cultivars subjected to $0,0.5,1.0$ and $2.0 \mathrm{Mm}$ of SA to determine the optimal concentration for developing novel mutants.

Materials and methods: The optimal dose of SA mutagen was found to be $2.0 \mathrm{mM}$, resulting in a $42 \%$ reduction in callus fresh and dry weight. The developed callus was subjected to five different salinity levels using $\mathrm{NaCl}\left(6,8,10,12\right.$ and $\left.14 \mathrm{dS} \mathrm{m}^{-1}\right)$.

Results: Mutants showed a significant decrease in the percentage of regenerated plants under salinity stress conditions. The used SSR markers approved the genetic diversity between the original and the mutants of the two cultivars (Al-Iraq and Tamooz 2) growing under normal and salinity stress. The presences and the absence of some fragments was prominent in plants derived from immature embryos of the two cultivars tested in salinity conditions. The used SSR markers (cfd 9, cfd4, cfd1 wmc405, PYL5, HKT1, HVA1 and htk1) were so efficient in distinguishing between the original and tissue culture-derived plants. Furthermore, the experienced SA levels induced a higher rate of mutant alleles in cv.

Conclusion: Al-Iraq with 19 mutant alleles than Tamooz 2 which showed only 13 mutant alleles. The current study represents an additional prove to the effectiveness of mutagens and tissue culture technique in developing novel variants with improved performance under stress conditions.
\end{abstract}

Keywords: Wheat, Immature Embryos, Salt Stress, Sodium Azide, SSR.

\section{Introduction}

Wheat Triticumaestivum is one of the most important and widely cultivated grain crops contributing effectively in feeding human populations around the world. Wheat as a field crop, is moderately sensitive to salt stress which adversely affects the crop productivity and quality due to a series of physiological and biochemical changes (2).

Increased salinity in the growing environment results in abiotic stress known as salt stress impairing the absorption of water and nutrients by plant cells due to imbalance in the osmotic and ionic balance that directly reflected in the growth and normal development of a plant (24). As in many abiotic stresses, salinity damages are mostly depending on the stress intensity and duration, as well as the nature of genetic background that confer the ability to avoid and/or escape un preferred environmental conditions (1).

However, the mechanisms lying behind salinity stress still poorly understood (10).

Salinity tolerance is a quantitative trait controlling by several genes and can be transmitted across subsequent generations, hence, can be improved via identifying and isolating key genes accountable for salt stress with aid of modern molecular techniques (18).

Crops improvement in general, and wheat in specific focusing on the utilization of the existed genetic diversity in the species gene pool and characterizing the desired traits essential for achieving stress tolerance (2) . Several mutagens like SA are attributed to different factors such as alterations of the metabolic activity, inhibitory action and disturbing plant growth regulators. Furthermore, SA ions can effectively interrupt oxidative phosphorylation (9). Plant tissue culture has contributed effectively in shortening breeding programs and overcoming many agricultural and environmental problems, like salinity.

Molecular markers are inestimable tools that commonly used and rapidly evolved in assessing genetic diversity within and between different plant species. The dominantly inheritance of SSR markers (Simple sequence repeats), great variance and richness of polymorphisms are main pillars in adopting and widely using of these markers (13).

The current work aimed to investigate the efficiency of sodium azide $\left(\mathrm{NaN}_{3}\right)$ in inducing genetic variation in the immature embryo of wheat (Triticum aestivum). 


\section{Materials and Methods}

Sodium azide $\left(\mathrm{NaN}_{3}\right)$ mutagen was used to induce genetic variations for salt stress in two of local wheat cultivars (AL-Iraq and Tamooz 2). Study was conducted in the lab. of tissue culture at the Genetic Engineering Institute-University of Baghdad-Iraq. Sodium Azide (SA) was prepared in four concentrations $(0,0.5,1$ and $2 \mathrm{mM})$ according to (8).

Immature wheat seeds of the two cultivars were soaked for five hours (14) then washed with autoclaved distilled water to get rid of the excess SA. Subsequently, the treated cultivar's seeds were disinfected superficially with ethanol $(70 \%)$ for 1 min., followed by sodium hypochlorite $(\mathrm{NaOCl})$ at a concentration of 4.2\% for $15 \mathrm{~min}$. Then, seeds were rinsed three times with autoclaved distilled water, each for $5 \mathrm{~min}$.

Embryos were separated from the treated seeds of the two cultivars and germinated on MS media supplemented with $2 \mathrm{mg} \mathrm{l}^{-1}$ 2,4-Dichlorophenoxy acetic acid solidified with $7.0 \mathrm{~g} \mathrm{l}^{-1}$ agar in a rate of 15 embryo per petridish. For callus induction, cultures were incubated in darkness for a week at $25 \pm 2{ }^{\circ} \mathrm{C}$. Then it was exposed to 16 hours of light (1000 lux) and 8 hours of dark. After eight weeks, the induced callus was transferred to a new MS medium supplemented with $0.4 \mathrm{mg} \mathrm{l}^{-1}$ 2,4-Dichlorophenoxy acetic acid, $0.8 \mathrm{mg} \mathrm{l}^{-1}$ of banzyl amino purine (BAP) and three levels of $\mathrm{NaCl}$ which was $\left(6.0,8.0,12.0\right.$ and 14) $\mathrm{dS} \mathrm{m}^{-1}$. Six weeks later, the mutant and stressed cultures were transferred to a regeneration media supplemented with $300 \mathrm{mg}^{-1}$ casein hydrolysate, $30 \mathrm{~g} \mathrm{l}^{-1}$ sucrose and $6 \mathrm{~g}^{-1}$ agar. Cultures were incubated at $25 \pm 2{ }^{\circ} \mathrm{C}$ under cool-white fluorescent light conditions for 8 weeks, and then the regenerated cultures were transferred to a new 1/2 MS media to induce root formation. Subsequently, the rooted seedlings were grown in 1:1 sand and Patmos pots.

\section{Total DNA Extraction}

Total genomic DNA was extracted from the young leaves of all studied treatments using mini kit (Plant), (Geneaid Biotech Ltd.). Quality and quantity of the extracted DNA was checked by using Nanodrop according to the following formulas (21).

- DNA concentration $(\mu \mathrm{g} / \mathrm{ml})=$ O.D. $260 \mathrm{~nm} \times 50 \times$ Dilution factor

- DNA purity ratio $=$ O.D.260/O.D.280

DNA samples were diluted to a final concentration of $50 \mathrm{ng} / \mu \mathrm{l}$ for PCR reaction. Eight forward and reverse SSR primers (Table 1) supplied by Alpha DNA-Canada were diluted with deionized distilled water to a final concentration of $10 \mathrm{pmol} / \mu \mathrm{l}$.

Table (1): The used eight SSR primers for the amplification of wheat cultivars

\begin{tabular}{|c|c|c|c|}
\hline Primer name & $F / R$ & 5'-'3 Sequence & Locus \\
\hline \multirow{2}{*}{ cfd1 } & $\mathbf{F}$ & ACCAAAGAACTTGCCTGGTG & \multirow{2}{*}{ 6A/2D } \\
\hline & $\mathbf{R}$ & AAGCCTGACCTAGCCCAAAT & \\
\hline \multirow{2}{*}{ cfd4 } & $\mathbf{F}$ & TGCTCCGTCTCCGAGTAGAT & \multirow{2}{*}{ 3B } \\
\hline & $\mathbf{R}$ & GGGAAGGAGAGATGGGAAAC & \\
\hline \multirow{2}{*}{ cfd9 } & $\mathbf{F}$ & TTGCACGCACCTAAACTCTG & \multirow{2}{*}{ 3D } \\
\hline & $\mathbf{R}$ & CAAGTGTGAGCGTCGG & \\
\hline \multirow{2}{*}{ wme 405} & $\mathbf{F}$ & GTGCGGAAAGAGACGAGGTT & \multirow{2}{*}{ 1D/7D } \\
\hline & $\mathbf{R}$ & TATGTCCACGTTGGCAGAGG & \\
\hline \multirow{2}{*}{ PYL5 } & $\mathbf{F}$ & GAGGCTCGAGATCTTGGACG & \multirow{2}{*}{ - } \\
\hline & $\mathbf{R}$ & GAAGGTTGCACCGGACGATA & \\
\hline \multirow{2}{*}{ htk1 } & $\mathbf{F}$ & CGGTAAATAGCAGTTGCGGC & \multirow{2}{*}{ - } \\
\hline & $\mathbf{R}$ & TTCCAGGATTTACCCGTGGC & \\
\hline \multirow{2}{*}{ HKT1 } & $\mathbf{F}$ & AGGACGCGGGTAGTAGAACT & \multirow{2}{*}{ - } \\
\hline & $\mathbf{R}$ & CACATTCCCATAAGCGCTGC & \\
\hline \multirow{2}{*}{ HVA1 } & $\mathbf{F}$ & ACCAGAACCAGGGGAGCTAC & \multirow[b]{2}{*}{ - } \\
\hline & $\mathbf{R}$ & TGGTGTTGTCCCCTCCCATG & \\
\hline
\end{tabular}


The single PCR reaction was in volume of $25 \mu \mathrm{l}$ containing $12.5 \mu \mathrm{l}$ of Green MasterMix (2X PCR buffer; $\mathrm{pH}=8.5)$, dNTPs $(400 \mu \mathrm{M})$ and Taq polymerase $(5 \mathrm{U}), 2.0 \mu \mathrm{l}$ total genomic DNA, $1.5 \mu \mathrm{l}$ of each $10 \mathrm{pmol} / \mu \mathrm{l}$ SSR primer. Subsequently, nuclease-free water was used to complete each reaction volume to $25 \mu 1$. Thermal profile was as following: Initial denaturation and denaturation at $94^{\circ} \mathrm{C}$ for 4 and 1 min., respectively. Annealing step was at $55^{\circ} \mathrm{C}$ for 1 min., extension and final extension was at $72^{\circ} \mathrm{C}$ for 1 and 10 min., respectively.

At the end of PCR program, $10 \mu \mathrm{l}$ from each amplified product was loaded in $1.5 \%$ agarose gel along with $1 \mathrm{~kb}$ DNA ladder. Electrophoresis was conducted for 2-3 hours on 5 volt $\mathrm{cm}^{-1}$. Agarose gel was visualized on UV transilluminator and documented with gel documentation system.

\section{Statistical Analysis}

Results of SSR was represented in binary data of 0 to the existed fragment and 1 to the absent. Polymorphic information content (PIC), major allele frequency and number of alleles were estimated using PowerMarker (ver. 3.7). Differences were tested according to the least significant deviation (LSD) in Complete Randomized Design (CRD).

\section{Results and Discussion}

\section{Effect of SA in callus fresh weight}

Results in Table (2) showed that the induced callus of cv. Tamooz 2 achieved the highest mean of fresh weight of $91.9 \mathrm{mg}$ compared to Al-Iraq cv. which gave about half of that value (53.9 mg), (Figure 1). The control treatments of both cultivars (Al-Iraq and Tamooz 2) were superior with the maximum mean of fresh weight $(101.4 \mathrm{mg})$.

Generally, fresh weight of the treated cultivars decreased in response to increase dosage of mutagen reaching $2 \mathrm{~mm}$ which caused the highest reduction in the fresh weight $(42.8 \mathrm{mg})$. The reduction in callus fresh weight of both cultivars may be due to the physiological and genetic effects of SA mutagen via affecting cell tissue development.

Such effects may resulted in major alterations in physiological pathways through intercepting oxidative phosphorylation, hence actively participating ATP generating necessary for mitosis.

Furthermore, SA may affected important enzymes such as peroxidase, cytochrome oxidase and catalase and/or inhibits the transport of peripheral electrons and protons of ATPase, causing sharp decline in cell energy status (11). The energy shortage is reflected on key biological processes, like DNA transcription and translation, ultimately production of proteins.

The more exposed to sodium azide negatively affects the photosynthesis rate and the sugar delivering that stumble Krebs cycle, leading to a large deficit in energy level and finally the non-building of ATP leading to low level of mitosis and inhibiting the growth rate. In addition, SA may severely damage single DNA strand (3). This effect puts surplus pressure on the cell to provide more energy necessary for efficient work of the DNA ligase enzyme to repair the damaged DNA.

SA may lead to the loss of one or more nucleotides that commonly known as point mutation (23). In such cases, changes in the sequence of amino acids will occur, therefore the synthesized protein and/or enzyme will differ (6).

The physiological and genetic alterations in response to the increased concentration of SA can be easily noted and the concentration of $2 \mathrm{mM}$ was the most influential in callus formation in both cultivars. These changes may result in the induction of mutant plants through the development of tissues susceptible to mutation that may be able to survive under inappropriate environmental conditions (16).

Table (2): Effect of SA in callus fresh weight (mg) of two wheat cultivars

\begin{tabular}{c|cccc|c}
\hline \multirow{2}{*}{ Cultivars } & \multicolumn{4}{|c|}{ Sodium Avide (SA) Con. mM } & \multirow{2}{*}{ Mean } \\
\cline { 2 - 5 } & Control & $\mathbf{0 . 5}$ & $\mathbf{1}$ & $\mathbf{2}$ & $\mathbf{5 3 . 9}$ \\
\hline Al-Iraq & $\mathbf{7 9 . 2}$ & $\mathbf{5 4 . 8}$ & $\mathbf{5 0 . 8}$ & $\mathbf{3 0 . 7}$ & $\mathbf{9 1 . 9}$ \\
\hline Tamooz 2 & $\mathbf{1 2 3 . 7}$ & $\mathbf{9 7 . 2}$ & $\mathbf{9 1 . 7}$ & $\mathbf{5 4 . 8}$ & $\mathbf{4 2 . 8}$ \\
\hline Mean & $\mathbf{1 0 1 . 4}$ & $\mathbf{7 4 . 0}$ & $\mathbf{7 3 . 3}$ & Int. NS \\
\hline LSD 5\% & Con. 15.01 & Cv. 10.61 & & \\
\hline
\end{tabular}




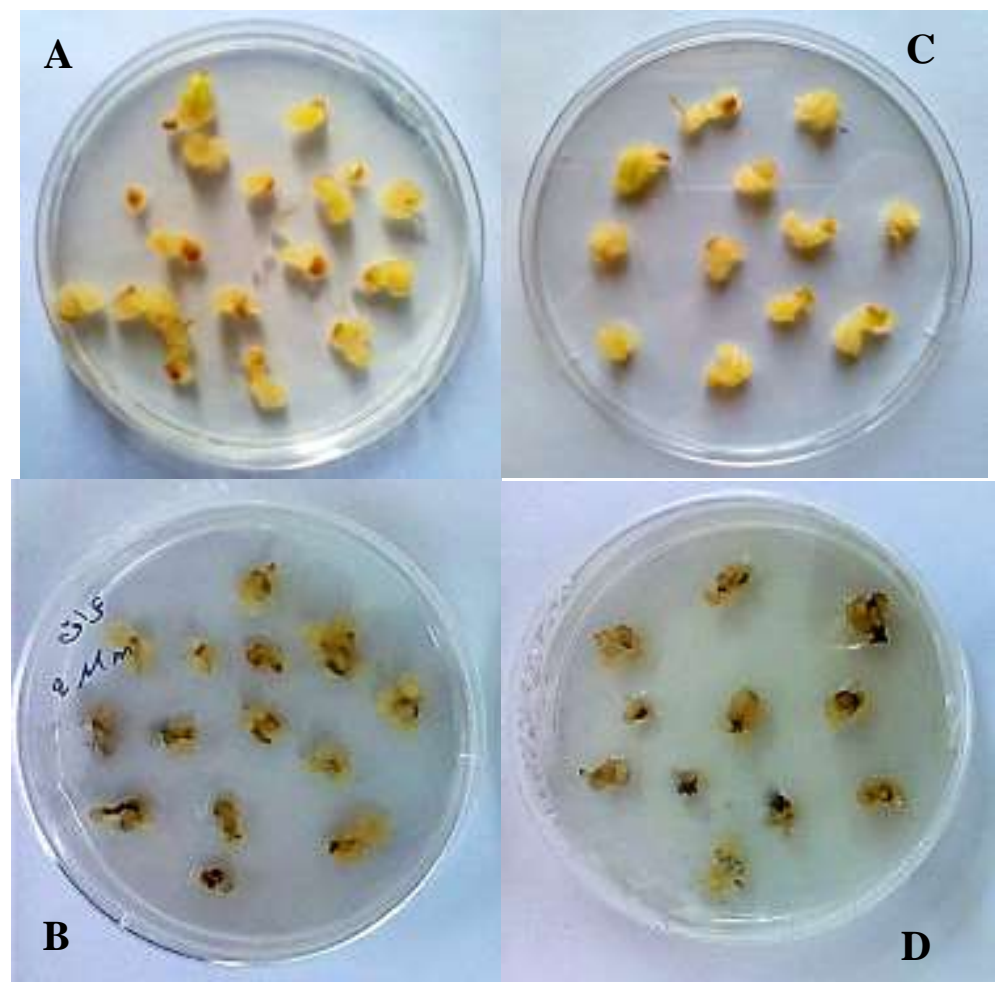

Figure (1): Callus induction in Al-Iraq and Tamooz2 wheat cultivars on solid agar MS medium after two weeks

A: Al-Iraq callus cultures originated from seeds non-treated with 2 mM SA.

B: Al-Iraq callus cultures originated from seeds treated with 2 mM SA.

C: Tamooz2 callus cultures originated from seeds non-treated with 2 mM SA.

D: Tamooz2 callus cultures originated from seeds treated with 2 mM SA.

\section{Effect of SA in callus dry weight}

Results presented in Table (3) approved the significant superiority of cv. Tamooz 2 in callus dry weight over cv. Al-Iraqi that showed the minimum value $(4.97 \mathrm{mg}$ and $3.65 \mathrm{mg}$, respectively). From the same table, SA treatments had significant effects in callus dry weight as control showed the maximum mean $(5.52 \mathrm{mg})$, meanwhile the highest SA concentration $(2 \mathrm{mM})$ was in negative relationship with callus dry weight scoring the lowest mean for the studied trait in both cultivars $(2.82 \mathrm{mg})$. These findings are consistent with that stated by (7), where higher concentrations of SA found to negatively attribute in callus dry weight.

Table (3): Effect of SA in callus dry weight (mg) of two wheat cultivars

\begin{tabular}{|c|c|c|c|c|c|}
\hline \multirow{2}{*}{ Cultivars } & \multicolumn{4}{|c|}{ Sodium Azide (SA) Con. mM } & \multirow{2}{*}{ Mean } \\
\hline & Control & 0.5 & 1 & 2 & \\
\hline Al-Iraq & 4.58 & 4.54 & 3.44 & 2.06 & 3.65 \\
\hline Tamooz 2 & 6.46 & 5.08 & 4.76 & 3.58 & 4.97 \\
\hline Mean & 5.52 & 4.81 & 4.10 & 2.82 & \\
\hline LSD $_{5 \%}$ & Con. 0.58 & Cv. 0.41 & & Int. NS & \\
\hline
\end{tabular}

\section{Regeneration of plantlets from $\mathrm{NaCl}$ tolerant calli}

The regeneration rate was significantly affected by SA and salt stress (Table 4). In this context, the results indicated a clear superiority of cv. Tamooz 2 as it exposed the highest rate of regenerated plants against $\mathrm{cv}$. Al-Iraq (Figure 2).

In the same manner, the increased concentration of saline in the cultural medium had a significant role in reducing regeneration rate, where the salinity level of $14 \mathrm{dS} \mathrm{m}^{-1}$ showed the minimum regeneration rate for both cultivars. These results are stated in previous studies on several crops species, including rice $(17,20)$, wheat (5), sugarcane (15) and peas (19). 
Table (4): Effect of salinity in regeneration rate of two wheat cultivars

\begin{tabular}{c|ccccc|c}
\hline \multirow{2}{*}{ Cultivars } & \multicolumn{7}{|c|}{ Salinity $\left(\mathrm{dS} m^{-1}\right)$} & \multirow{2}{*}{ Mean } \\
\cline { 2 - 6 } & $\mathbf{6}$ & $\mathbf{8}$ & $\mathbf{1 0}$ & $\mathbf{1 2}$ & $\mathbf{1 4}$ & \\
\hline Al-Iraq & $\mathbf{0 . 7 0}$ & $\mathbf{0 . 5 6}$ & $\mathbf{0 . 2 6}$ & $\mathbf{0 . 2 0}$ & $\mathbf{0 . 1 3}$ & $\mathbf{0 . 3 7}$ \\
\hline Tamooz 2 & $\mathbf{0 . 7 9}$ & $\mathbf{0 . 6 7}$ & $\mathbf{0 . 2 3}$ & $\mathbf{0 . 2 0}$ & $\mathbf{0 . 1 0}$ & $\mathbf{0 . 4 0}$ \\
\hline Mean & $\mathbf{0 . 7 4}$ & $\mathbf{0 . 6 2}$ & $\mathbf{0 . 2 5}$ & $\mathbf{0 . 2 0}$ & $\mathbf{0 . 1 1}$ & \\
\hline LSD $_{\text {5\% }}$ & Sal. 0.15 & Cv. 0.09 & & Int. 0.21 & & \\
\hline
\end{tabular}

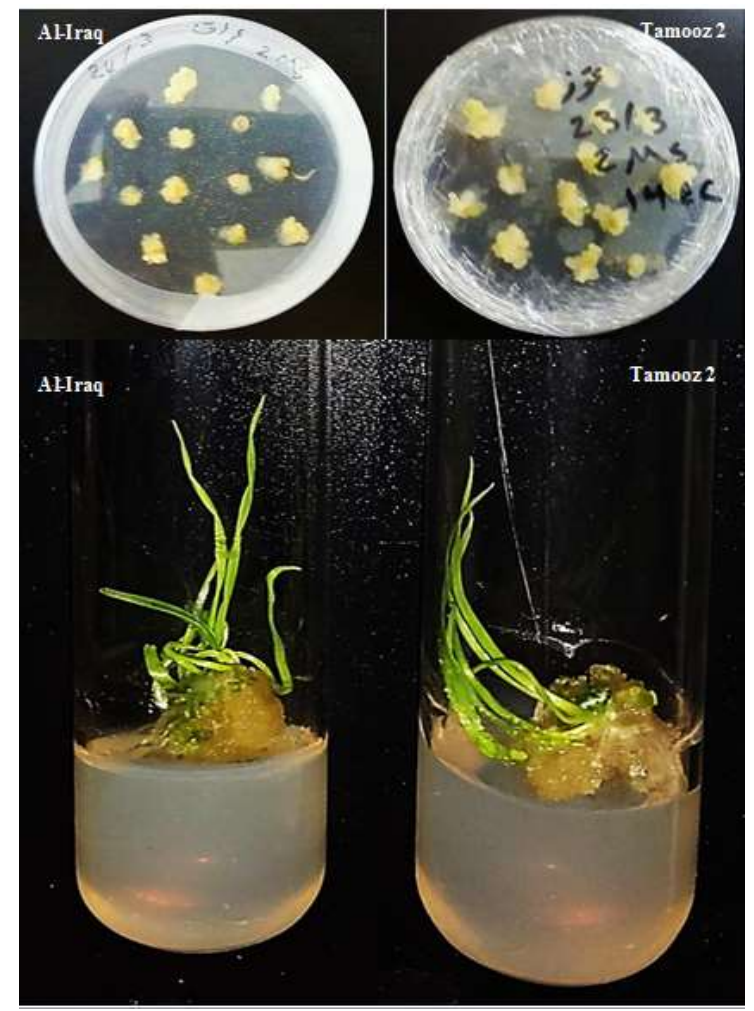

Figure (2): Callus induction from immature seeds (Al-Iraq and Tamooz 2) treated with 2 mM SA then exposed of stress salt level of $14 \mathrm{ds.m}-1$ and shoot regeneration from callus mutagen with $2 \mathrm{mM}$ SA on $14 \mathrm{ds} \mathrm{m}^{-1} \mathrm{NaCl}$ on solid agar MS medium after four weeks

\section{SSR results of wheat cultivars}

Molecular results of SSR markers (Figure 3) indicated the variability of mutated plants of Al-Iraq cultivar under salt stress against their ancestor original plants. As seen in Table (5), the variability was in perspective of number, location and molecular size of the amplified fragments.

Generally, the mutant stressed plants expressed low number of alleles considering the used primers CDF4, CDF9, PYL5, htk1, HKT1 andHVA1,meanwhile the other primer (WMC405) acted in different way by detecting more alleles at different loci through the genomes of the mutated and stressed plants compared to the original plants of the same cultivar (Al-Iraq). 


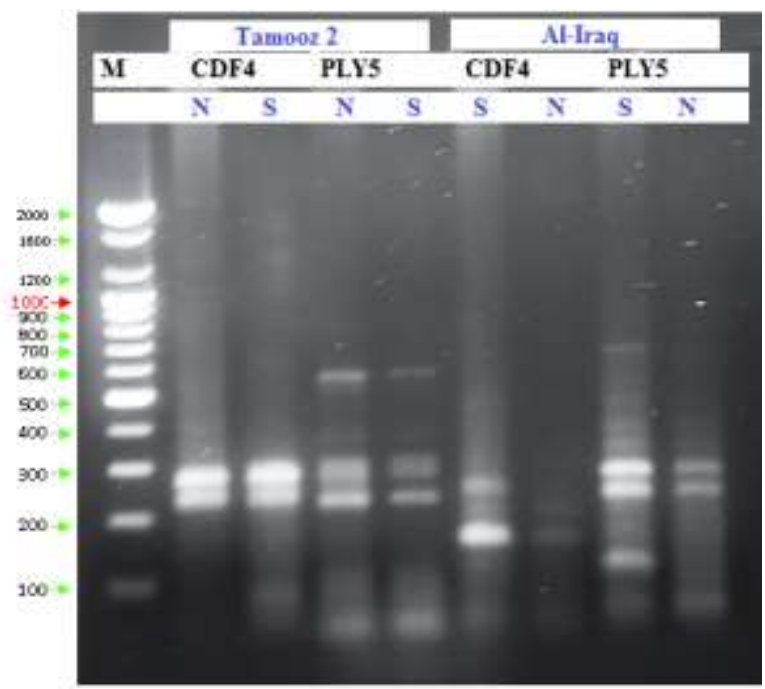

Figure (3): PCR results using selected SSR markers in Al-Iraq and Tamooz 2 wheat cultivars under normal $(\mathrm{N})$ and shoots regenerated from callus cultures (treated with $2 \mathrm{mM} \mathrm{SA}$ and salt stressed level $\left.14 \mathrm{ds.m}{ }^{-1}\right)(S)$ conditions

The differences between the original plants and tissue culture-descended plants were not only shown in the loss of amplified fragments, but the differences were observed in the locus of alleles and its molecular size too. For example, the CDF9 marker succeeded in amplifying four fragments in the original plants with molecular sizes ranged from 100 to $700 \mathrm{bp}$, whereas it detected only one fragment in the tissue culturederived plants with a small molecular size $(50 \mathrm{bp})$. The using of HVA1 marker resulted in the characterization of two fragments in the original plants with a molecular size ranged between 150 and 200 bp. The tissue culture-derived plants expressed two fragments by using the previously mentioned marker which differed in respect of locus and molecular size (100-250 bp).

Five fragments showed by WMC405 marker in the original plants with molecular size ranged from 100 to $500 \mathrm{bp}$, while the amplified fragments reached seven in the tissue culture-derived plants with higher molecular sizes ranged between $150-700 \mathrm{bp}$. The loss of fragments in some treatments may be due to the absence of complementary sequence of the used marker in the targeted DNA as a result of small deletions and/or insertions type of mutations in response to sodium azide treatments (22).

The molecular results pointed to a clear genetic variations of the regenerated mutant plants growing in salt stressed medium in contrast to original plants of cv. Tamooz 2 (Figure 3) in respect of number, locus and molecular size of the amplified fragments with the aid of SSR markers (CDF1, CDF4, CDF9, htk1, HKT1, HVA1 and WMC405).

The used molecular markers (CDF1, CDF4, CDF9, htk1, HKT1 and HVA1) tended to produce excess fragments across the mutant genomes under salty conditions compared to the original genomes. In contrast, the PYL5 primer exposed a different response to SA treatment in term of losing one annealing site along with the mutant DNA (Figure 3). The WMC405 primer was not able to distinguish between tissue culturederived plants and their originals.

The observed variations between the original and tissue culture-derived plants are basically reflected the mutagenic effect of sodium azide which may enhance the expression of some genes responsible for salt stress tolerance at a higher levels. For this reason, a plant that may not be able to grow in salty environment is due to the loss or gain of function mutations.

It is an effective tool to produce novel mutants that may contribute in improving yield, quality traits and tolerance to biotic and abiotic stresses, and ultimately sustainable crop production $(12,4)$.

\section{Genetic analysis of SSR data}

Results of genetic analysis indicated the existence of genetic diversity between tissue culture-derived plants of the two cultivars (Al-Iraq and Tamooz 2) in respect of mutant alleles. The used mutagen was more effective in producing mutant alleles in cv. Al-Iraq than Tamooz 2 (13 and 19 alleles, respectively), (Table 5). The genetic variations between the two cultivars may result in several alterations with nucleotide sequence by addition, deletion and rearrangement in the DNA of the studied cultivars. Two of the used SSR markers, cfd 9 and cfd 4 succeeded in identifying a higher number of mutant alleles in cv. Al-Iraq (7 and 6 alleles, respectively) compared to Tamooz 2. Meanwhile, Wmc405 marker was more efficient in diagnosing the highest number of mutant alleles in cv. Tamooz 2 (4 alleles). 
Table (5): Effect of sodium azide in the number of mutant alleles between the two treatments for each cultivar

\begin{tabular}{|cccc|}
\hline Primer name & Al-Iraq & Tamooz 2 & Mean \\
\hline cfd1 & - & 1 & 1 \\
\hline cfd4 & 5 & 1 & 6 \\
\hline cfd9 & 5 & 2 & 7 \\
\hline wmc405 & 2 & 4 & 6 \\
\hline PYL5 & 1 & 1 & 2 \\
\hline htk1 & - & 1 & 1 \\
\hline HKT1 & 2 & 3 & 5 \\
\hline HVA1 & 4 & - & 32 \\
\hline Mean & 19 & 13 & 4 \\
\hline
\end{tabular}

\section{Effect of sodium azide in RP and PIC values}

Variations in fragments number, allele's number,RP and PIC values were detected using the eight SSR markers. The estimated values of PIC is presented in table 6 indicated the used primer efficiency in distinguishing between the studied cultivars in response to SA treatments. Wmc405, HKT1, and HVA1 markers showed a higher PIC value, whereas the cfd1 marker exposed the lowest value. The superiority of the wmc405, HKT1, and HVA1 in PIC values may indicate their ability to diagnose salinity-tolerant cultivars and may be used in future studies to develop novel wheat genotype.

Results approved that HKT1 and HVA1 were superior in giving the highest number of alleles while the cfd1 marker gave the lowest number of alleles. CFd4, PYL5, HKT1 and HVA1 amplified the highest number of fragments and had a higher RP value, while cfd1 marker owned the lowest values of amplified fragments and RP. From table 5, RP values were positively correlated with the number of produced fragments, with a correlation coefficient reached 0.89 indicating that RP can be a function of fragments number. Markers with higher concurrence of PIC and RP values represent an efficient molecular tool serving in allele's diagnosis. Thus, HKT1 and HVA1 markers are the best in diagnosing salinity tolerant genotypes.

Table (6): The amplified fragments, alleles, PIC and RP of the used SSR markers in cv. wheat

\begin{tabular}{ccccc}
\hline SSR Marker & Fragments No. & Alleles No. & PIC & RP \\
\hline CDF1 & 7 & 3 & 1.37 & 4.5 \\
\hline CDF4 & 18 & 9 & 3.5 & 9.0 \\
\hline CDF9 & 13 & 9 & 3.75 & 7.0 \\
\hline WMC405 & 14 & 9 & 4.0 & $\mathbf{7 . 0}$ \\
\hline PYL5 & 18 & 9 & 3.75 & 9.0 \\
\hline htk1 & 11 & 6 & $\mathbf{2 . 8 7}$ & $\mathbf{5 . 5}$ \\
\hline HKT1 & 19 & 10 & 4.0 & 9.0 \\
\hline HVA1 & 18 & 10 & 4.37 & 8.5 \\
\hline
\end{tabular}




\section{References}

1. Abbas G, Chen Y, Khan FY, Feng Y, Palta JA, Siddique KHM. Salinity and low phosphorus differentially affect shoot and root traits in two wheat cultivars with contrasting tolerance to salt. Agronomy. (2018);8:155.

2. Abhinandan K, Skori L, Stanic M, Hickerson NMN, Jamshed M, Samuel MA. Abiotic Stress signaling in wheat-an inclusive overview of hormonal interactions during abiotic stress responses in wheat. Front. Plant Sci. (2018); 9:734.

3. Adams CA, Broman JH, Rinne RW. Starch metabolism in developing and germinating soybean seeds is independent of a- amylase activity. Ann. Bot(1981); 48: 433-440.

4. Adebola MO. Mutagenic effect of sodium azide (NaN3) on morphologic characteristics of tomato Lycopersicum esculentum The international J.RJSITM. (2013); 2 (4):1-5.

5. Akhtar S, Chughtai UR, Chudhry Z, Munawwar MH, Hussain M. Callus induction and regeneration in wheat cultivars under sodium and calcium chlorides salt stress. Sarhad J. Agric. (2007); 23 (3):650-654.

6. Al-Qurainy F, Khan S. Mutagenic effect of sodium azide and its application in crop improvement. World Applied Science J. (2009);6(12):1589-1601.

7. Al-Shmarey IAH. In Vitro induction and assessment of genetic variation form drought tolerance in some wheat(Triticum aestivum L.)cultivars.Coll.Of Sci. . Agr., Un. of Baghdad. (2007):156.

8. Boyadziev PC, Naidenova MP, Pouleva D, Perfanov K. Callus genesis and regeneration anther culture of rice treated with physical and chemical mutagens. Institute of Introduction and Plant Genetic. (1987); $239-343$.

9. Dubey S, Bist R, Misra S. Sodium azide induced mutagenesis in wheat plant. World J. of Pharmacy and Pharmaceutical Sci. (2017); 6(10): 294-304.

10. Errabii T, Gandonou CB, Bouhdid S, Abrini J, Skali-Senhaji N. Callus growth and ion composition in response to long-term $\mathrm{NaCl}$-induced stress in two sugarcane (Saccharum sp.) cultivars. Int. J. Biotechnol. Mol. Biol. Res. (2018); 8(1): 1-9.

11. Gruszka D, Szarejko I, Maluszynski M. Chapter: Sodium Azide as a Mutagen. (2012); 159-166.

12. Khan S, Goyal S. Improvement of mungbean varieties through induced mutations. Afr. J. Plant Sci. (2009); 3: 174-180.

13. Liu G, Xie Y, Zhang D, Chen H.Analysis of SSR loci and development of SSR primers in Eucalyptus. J. For. Res. (2018); 29(2): 273-282.

14. Maluszynski M, Szarejko I, Bhatia RC, Nichterlein K, Lagoda PJL. Methodogies for generating variability part4: Mutation Techniques. (2009): 179.

15. Nikam A, Devarumath RM, Ahuja A, Babu H, Shitole MG, Suprasanna B. Radiation-induced in vitro mutagenesis system for salt tolerance and other agronomic characters in sugarcane (Saccharum officinarum L.). J. Crop. (2015); (3): $46-56$.

16. Oraibi AG. Investigation of growth factors and DNA markers for drought tolerance in some rice (Oryza sativa L.) genotypes. Ph.D. Thesis, College of biotechnology. Univ. of Al-Nahrain. Baghdad. Iraq. (2013); 145.

17. Priya AM, Pandian SK, Ramesh M. Effect of $\mathrm{NaCl}$ on in vitro plant regeneration from embryogenic callus cultures of 'cv IR 64' indica rice (Oryza sativa L.). African J. of Biotechnology. (2011);10(36): 6947-6953.

18. Rahneshan Z, Nasibi F, Moghadam AA. Effects of salinity stress on some growth, physiological, biochemical parameters and nutrients in two pistachio (Pistaciavera L.) rootstocks. J. of Plant Interactions. (2018); 13(1): 73-82.

19. Rao S , Patil P. In Vitro Selection of Salt Tolerant Calli Lines and Regeneration of Salt Tolerant Plantlets in Mung Bean (Vigna radiata L. Wilczek), Biotechnology - Molecular Studies and Novel Applications for Improved Quality of Human Life, Prof. Reda Sammour, ISBN.(2012); 197-212.

20. Rattana K, Bunnag S. Differential salinity tolerance in calli and shoots of four rice cultivars. Asin J. of Crop Sci. (2015); 7(1): 48-60.

21. Sambrook J , Fritsch EF, Maniatis. Molecular cloning, 2nded Cold spring Harbor Laboratory Press, N. Y. (1989).

22. Şen A, Sarsu F. Genetic diversity in sodium azide induced wheat mutants studied by SSR markers. Trakya Univ. J. Nat. Sci. (2018);19(2): 129-135.

23. Słoczyńska K, Powroźnik B, Pękala E, Waszkie-lewicz AM. Antimutagenic compounds and their possible mechanisms of action. J. Appl Genetics . (2014); 14(19):8-9.

24. $\mathrm{Wu} \mathrm{H}$. Plant salt tolerance and $\mathrm{Na}^{+}$sensing and transport. The Crop J.. (2018) 6: 215 -225. 